\title{
Home assessment of peak inspiratory flow through the Turbohaler in asthmatic patients
}

\author{
R J Meijer, Th W van der Mark, B J Aalders, D S Postma, G H Koëter
}

\begin{abstract}
Background - The efficacy of dry powder inhalers depends on the patient's inspiratory flow. Drug delivery from the Turbohaler (Turbuhaler in some countries), a multidose powder inhaler, is optimal at flows of $>401 / \mathrm{min}$. The aim of this study was to investigate the peak inspiratory flow that can be generated by asthmatic patients through the budesonide Turbohaler $\left(\mathbf{P I F}_{\mathrm{TBH}}\right)$ during maintenance treatment at home.

Methods - Thirty asthmatic patients, consecutively recruited from the outpatient clinic, inhaled their maintenance dose of $800(n=16)$ or $1600 \mu g / d a y(n=14)$ for two months or one month, respectively. The Turbohaler was connected to a modified Vitalograph Compact installed at home to obtain printed PIF $_{\mathrm{TBH}}$ values for all inhalations. Peak expiratory flow (PEF) was measured twice daily.

Results - Flows were remarkably constant with individual mean PIF $_{\mathrm{TBH}}$ values ranging from $55 \mathrm{l} / \mathrm{min}$ to $95 \mathrm{1} / \mathrm{min}$. Only 13 of the $5248 \mathrm{PIF}_{\mathrm{TBH}}$ recordings taken at home (three patients) were $<401 / \mathrm{min}$ and all were $>301 / \mathrm{min}$. Weekly mean morning PEF values ranged from $1141 / \mathrm{min}$ to $7331 / \mathrm{min}$. PIF $_{\text {TBH }}$ values could not be accurately predicted from lung function parameters in individual patients.
\end{abstract}

Conclusions - In a group of stable asthmatic patients inspiratory flow rates rarely fell below the $401 / \mathrm{min}$ needed to operate a Turbohaler.

(Thorax 1996;51:433-434)

Department of Pulmonary Diseases, University Hospital Groningen, 9700EZ Groningen, The

Netherlands

R J Meijer

Th W van der Mark

B J Aalders

D S Postma

G H Koëter

Correspondence to: Dr R J Meijer.

Received 4 May 1995 Returned to authors 20 July 1995 Revised version received 19 October 1995 Accepted for publication 5 December 1995
Key words: asthma, peak inspiratory flow, Turbohaler.

Inhalation of aerosolised drugs is widely used in the treatment of asthma. The inhaler systems can be divided into three groups: (1) pressurised metered dose inhalers, (2) dry powder inhalers, and (3) nebulisers. The Turbohaler (Turbuhaler in some countries), a multidose dry powder inhaler, is a device from the second group. The clinical effect and deposition of budesonide is higher when using a Turbohaler than when using a pressurised metered dose inhaler. ${ }^{12}$ However, a sufficient peak inspiratory flow through the inhaler $\left(\mathrm{PIF}_{\mathrm{TBH}}\right)$ is required to achieve a large percentage of small respirable particles of the drug and an optimal lung deposition. ${ }^{34}$ Due to the built-in resistance of the Turbohaler this could be a problem in asthmatic patients. Several studies have shown that a flow ranging from 28 to $361 / \mathrm{min}$ is sufficient to give good lung deposition and clinical efficacy. ${ }^{24-8}$ These studies, however, were all performed under supervision of a physician or technician. We have therefore investigated whether a sufficient $P_{I F} F_{T B H}$ is generated when patients use a Turbohaler unsupervised at home.

\section{Methods}

Thirty patients with asthma according to ATS criteria $^{9}$ who attended our outpatient clinic were consecutively recruited into the study. The clinical characteristics of the patients are given in the table. All patients had used a budesonide Turbohaler for at least two months before the study and continued their maintenance dose of budesonide during the study. The study was approved by the local ethics committee of our hospital and all patients gave written informed consent.

\section{CLINICAL ASSESSMENTS}

Spirometric measurements were made at the first visit. The patients received a patient diary, a mini-Wright peak flow meter (Clement Clarke Int Ltd, UK), and study medication, and were supplied with two new inhalers instead of their own Turbohaler. One was to be used in series with a calibrated pneumotachograph (Vitalograph Ltd, Buckingham, UK) connected to an adaptor containing a Turbohaler, the other in case access to the first one was not possible. Patients were instructed to inhale deeply and forcefully through the Turbohaler connected to the adaptor and

Baseline characteristics of the patients

\begin{tabular}{lll}
\hline & Mean & Range \\
\hline No. of patients & 30 & \\
Male/female & $8 / 22$ & \\
No. with positive skin test & 22 & \\
Age (years) & 31 & $18-62$ \\
$\mathrm{FEV}_{1}(\%$ pred) & $87 \cdot 6$ & $48 \cdot 8-117 \cdot 4$ \\
PC $_{20}$ histamine* $(\mathrm{mg} / \mathrm{ml})$ & $1 \cdot 15$ & $0 \cdot 2-5 \cdot 0$ \\
Duration of asthma (years) $_{\text {Turbohaler use (years) }}$ & $9 \cdot 0$ & $0 \cdot 25-26 \cdot 2$ \\
$800 / 1600 \mu \mathrm{g} /$ day (no.) & $1 \cdot 3$ & $0 \cdot 2-3 \cdot 8$ \\
\hline
\end{tabular}

$\mathrm{FEV}_{1}=$ forced expiratory volume in one second; $\mathrm{PC}_{20}=\mathrm{con}$ centration of histamine causing a $20 \%$ fall in $\mathrm{FEV}_{1}$.

* 30 minute method, geometric mean

** Dose of budesonide used as maintenance therapy. 
Figure 1 Distribution of all peak inspiratory flow values through the Turbohaler $\left(P I F_{T B H}\right)$.

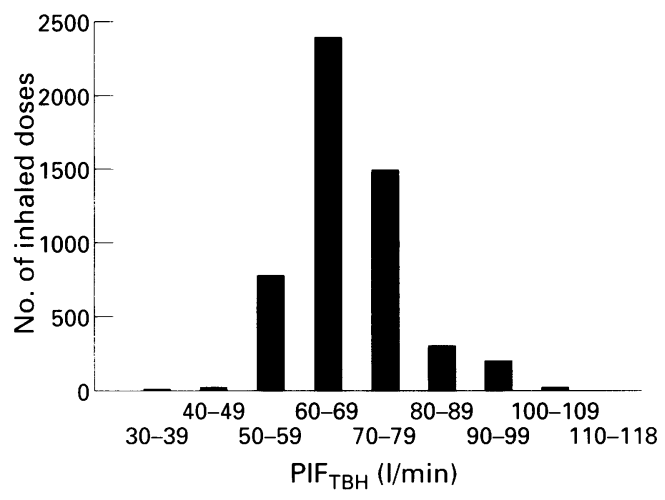

instructions were given to use the Vitalograph. During the study (at home) the $\mathrm{PIF}_{\mathrm{TBH}}$ value for each inhalation was printed out by the Vitalograph. Patients also measured their peak expiratory flow (PEF) twice daily. Patients were visited at home by the investigator after two days and again after two weeks. After 180-190 doses had been taken from their Vitalographconnected Turbohaler the patients visited the outpatient clinic and spirometric measurements were repeated and diary cards and study medication were collected.

\section{DATA ANALYSIS}

Correlations between lung function parameters were investigated by Pearson's product moment correlation after checking for normal distribution. The level of significance was $p<0 \cdot 05$.

\section{Results}

Twenty nine of the 30 patients completed the study; one could not complete the study due to an asthma exacerbation. The study lasted 23-60 days depending on dose (1600 or $800 \mu \mathrm{g} /$ day) used in the individual patient; 147-224 inhalations per patient were measured.

Patients inhaled through the Turbohaler with an average flow of $68 \mathrm{l} / \mathrm{min}$. The distribution of all $\mathrm{PIF}_{\mathrm{TBH}}$ values is presented in fig 1 . Individual mean $\mathrm{PIF}_{\mathrm{TBH}}$ values ranged from 55 to $95 \mathrm{l} /$ $\mathrm{min}$, and extreme values on single days were $30-118 \mathrm{l} / \mathrm{min}$. A PIF $\mathrm{TBH}_{\mathrm{TB}}$ of less than $40 \mathrm{l} / \mathrm{min}$ was registered in three patients in 13 out of 5248 inhalations $(0 \cdot 25 \%)$. Morning and evening $\mathrm{PIF}_{\mathrm{TBH}}$ values remained remarkably constant during the study. The mean (SD) peak inspiratory flow without the Turbohaler at the first and last visit was 368 (108) $1 / \mathrm{min}$ and 383

Figure 2 Correlation between peak inspiratory flow through the Turbohaler $\left(P I F_{T B H}\right)$ and peak expiratory flow (PEF) at home. Data points are shown as individual means.

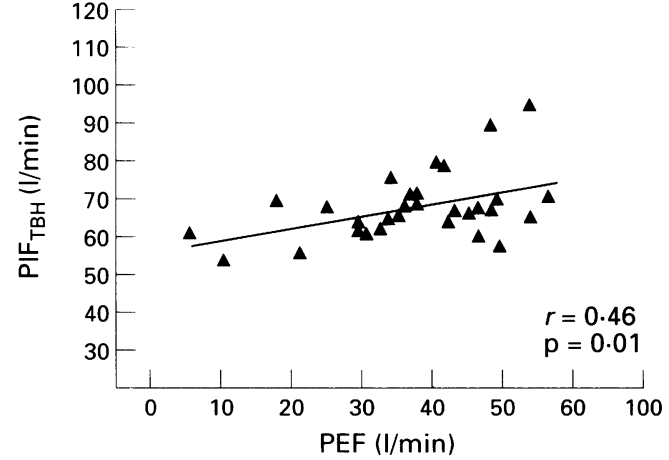

(103) $1 / \mathrm{min}$, respectively. The mean weekly (range) in PEF was 455 (115-726) $1 / \mathrm{min}$ in the morning and 460 (134-733) $1 / \mathrm{min}$ in the evening. The correlation between overall $\mathrm{PIF}_{\mathrm{TBH}}$ and overall PEF is shown in fig $2(r=$ $0 \cdot 46, p=0 \cdot 01)$. No statistically significant correlation between $\mathrm{PIF}_{\mathrm{TBH}}$ and percentage predicted forced expiratory volume in one second was found $(r=0 \cdot 18, \mathrm{p}=0.33)$. All lung function parameters improved slightly, but not significantly, during the study.

\section{Discussion}

The primary objective of this study was to examine the peak inspiratory flow generated by asthmatic patients during maintenance treatment at home with a Turbohaler $\left(\mathrm{PIF}_{\mathrm{TBH}}\right)$. Results were unlikely to have been affected by training as all patients were current users of the Turbohaler for a relatively long time. However, the presence of the pneumotachograph could be regarded as a cause of improved flow rates. In our opinion this could lead to a more regular use of budesonide but probably not to an increase in the value of $\mathrm{PIF}_{\mathrm{TBH}}$ since verbal stimulation during the measurements at home was absent in contrast to studies performed under direct supervision. The flow through the Turbohaler reached by the patients in our study is in accordance with other studies performed under supervision in the laboratory. ${ }^{4710}$ Even though the correlation between PEF and $\mathrm{PIF}_{\mathrm{TBH}}$ is statistically significant in our study, it is not possible to predict PIF $_{\mathrm{TBH}}$ accurately from expiratory variables. Previous studies have found a stronger correlation between these variables $^{710}$ which might suggest that even patients with low PEF values can use the Turbohaler effectively.

The results of this study show that asthmatic patients can produce a PIF $_{\mathrm{TBH}}$ value of more than $40 \mathrm{l} / \mathrm{min}$ at home, which is sufficient for optimal drug delivery through the Turbohaler.

Supported by a research grant from Astra AB

Agertoft L, Pedersen S. Importance of the inhalation device on the effect of budesonide. Arch Dis Child 1993;69:130-3.

2 Thorsson L, Edsbäcker S, Conradson TB. Lung deposition of budesonide from Turbuhaler is twice that from a pressurized metered-dose inhaler P-MDI. Eur Respir 71994 7:1839-44.

3 Persson G, Wirén JE. The bronchodilator response from inhaled terbutaline is influenced by the mass of small particles: a study on a dry powder inhaler (Turbuhaler). particles: a study on a dry pr

4 Pedersen S, Hansen OR, Fuglsang G. Influence of inspiratory flow rate upon the effect of a Turbuhaler. Arch Dis Child 1990;65:308-19.

5 Jaegfeldt $\mathrm{H}$, Andersson JAR, Trofast E, Wetterlin KIL Particle size distribution from different modifications of Turbuhaler. In: Newman SP, Morén F, Crompton GK, eds. A new concept in inhalation therapy. London: Medicom, 1987:90-9.

6 Engel T, Heinig JH, Malling HJ, Scharling B, Nikander K, Madsen F. Clinical comparison of inhaled budesonide delivered either via pressurized metered-dose inhaler or Turbuhaler. Allergy 1989;44:220-5.

7 Engel T, Heinig JH, Madsen, F, Nikander K. Peak inspiratory flow and inspiratory vital capacity of patients with asthma measured with and without a new dry-powder with asthma measured with and without a new dry-powd

8 Borgström L, Bondesson E, Morén F, Trofast E, Newman SP. Lung deposition of budesonide inhaled via Turbuhaler: a comparison with terbutaline sulphate in normal subjects. a comparison with terbutaline sulphate in normal subjects. Eur Respir f 1994;7:769-73.

9 Standards for the diagnosis and care of patients with chronic obstructive pulmonary disease (COPD) and asthma. $A m$ Rev Respir Dis 1987;136:225-44.

10 Brown PH, Greening AP, Crompton GK. Peak inspiratory flow rates in acute asthma: are they adequate for efficient use of a Turbuhaler. Thorax 1992;47:239P. 


\section{LETTERS TO THE EDITOR}

\section{Lung transplantation in patients with cystic fibrosis}

We read with interest the paper by Ryan $e t$ al (March 1996;51:302-5) describing their experience of pulmonary transplantation in patients referred from a single cystic fibrosis centre. We thought it would be useful to present similar data from a lung transplan centre serving several cystic fibrosis centres.

The Freeman Hospital Cardiopulmonary Transplantation Unit regularly assesses patients from six cystic fibrosis centres in the UK. To date we have assessed 137 patients on site, of whom only 12 have been considered unsuitable for transplantation. Of the 125 patients accepted, 36 have undergone pulmonary transplantation, 22 remain alive with an actuarial survival of $66 \%$ at two years and 38 have died awaiting transplantation. Fifty one patients are currently awaiting transplantation with 22 on the active list and 29 on the provisional list.

Our policy is to liaise closely with referring centres and review patients when the FEV falls below $30 \%$ predicted, when there is evidence of unusually rapid and progressive fall in $\mathrm{FEV}_{1}$, or when there is an increasing need for admission to hospital. Patients are placed on the provisional list when judged suitable for transplantation but are either too well or have correctable relative contraindications.

Shortage of donor organs continues to represent the major obstacle and cause of death associated with transplantation. The median wait from acceptance to transplantation is 242 days and our experience in cystic fibrosis is that, when actively listed, approximately $50 \%$ of patients will die before surgery.

We endorse the view that it is important to discuss with potential recipients their chances of receiving lung transplantation as well as the results of this procedure.

E GABBAY
J H DARK
N WRIGHTSON
P A CORRIS
Department of Respiratory Medicine,
Freeman Hospital, High Heaton,
Newcastle upon Tyne NE7 7DN, UK

\section{Chronic hypoxia and pulmonary rehabilitation}

We read with interest the editorial by $\mathrm{Dr}$ Wijkstra on pulmonary rehabilitation in the home (February 1966;51:117-18). We agree that accurate hospital assessment and selection of the patient with COPD is essential before enrolment into a pulmonary rehabilitation programme, whether performed as an inpatient, outpatient, or mainly in the home. However, Dr Wijkstra also suggests that patients with exercise hypoxaemia should be excluded from home programmes, which will include patients with more advanced COPD.

Few studies have investigated the effects of pulmonary rehabilitation in patients with severe COPD. In a recent controlled study of rehabilitation reported by Goldstein and col- leagues ${ }^{1}$ patients with a forced expiratory volume in one second $\left(\mathrm{FEV}_{1}\right)$ of less than $40 \%$ predicted were selected and showed improvements in exercise tolerance and quality of life after rehabilitation. Oxygen prescription during exercise was adjusted to maintain arterial oxygen saturation at $85-90 \%$ and rehabilitation continued at home after the initial inpatient programme. In a retrospective study patients with a mean $\mathrm{FEV}_{1}$ of $20 \%$ predicted with severe hypercapnia $\left(\mathrm{PaCO}_{2}>7.2 \mathrm{kPa}\right)$ showed increases in exercise capacity after physical training. ${ }^{2}$

Patients with more severe COPD have a greater impairment of quality of life related to the severity of their hypoxaemia, ${ }^{3}$ and considerable anxiety and depression which further impairs activities of daily living. This patient group may be particularly suitable for home pulmonary rehabilitation programmes, although outcome measures may differ in view of the greater degree of disability present. Ambulatory oxygen devices are widely available to correct hypoxaemia during physical training and we have used these in the home without complications. More controlled studies are required to assess selection, effectiveness, safety, and costs of rehabilitation in patients with advanced COPD.

1 Goldstein RS, Gort EH, Stubbing D, Avendano MA, Guyatt GH. Randomised controlled trial of pulmonary rehabilitation. Lancet $1994 ; 344$ : 1394-7.

2 Foster S, Lopez D, Thomas HM. Pulmonary rehabilitation in COPD patients with elevated $\mathrm{PCO}_{2}$. Am Rev Respir 1988;138:1519-23.

. fife in patients with COPD and severe hypoxaemia. Thorax 1995;51:44-7.

R GARROD

R GARNHAM J BESTALI

J A WEDZICHA Respiratory Care Unit London Chest Hospital, Bonner Road,

London $E 2$ 97X, UK

\section{BOOK REVIEW}

Occupational Lung Diseases. WKC Morgan, A Seaton. (Pp 680; \$89.50). Philadelphia: WB Saunders, 1995. 0-721-64671-9.

The first edition of this well regarded book was published in 1975 and the authors have revised the text each decade since. Although a number of other experts have contributed, the two authors have continued to be involved in writing most of the chapters which gives the book a refreshing fluency and continuity which is so often lacking in many modern day, multi-author, multi-volume texts.

The first third of the book concentrates on the history, epidemiology, physiology, and pathophysiology of occupational lung disease. These chapters are well written and provide first class instruction for those contemplating research into occupational lung disease. I particularly enjoyed Anthony Seaton's chapter on the history of occupational lung disease and Alan Gibbs' chapter on pathological reactions of the lung to dust. One minor criticism would be that the chapter on lung function is rather long and contains detailed information on pulmonary physiology readily available elsewhere.
The remainder of the book is dedicated to specific occupational lung diseases. Each chapter opens with an account of the history and a thorough review of the epidemiology before moving on to clinical and pathological aspects of the condition. The disease coverage is comprehensive rather than encyclopaedic, but this has the advantage of producing a book which is not too weighty, and which can equally be read in the library or used in the field.

For me, however, the real strength of this book is its ability to stimulate interest in, and then guide, research into occupational lung disease. This is an excellent text and is recommended. - RH

NOTICE

\section{Pharmacology of Asthma}

A course on the Pharmacology of Asthma organised by Professor Peter Barnes will be held at Imperial College School of Medicine at the National Heart and Lung Institute in collaboration with the Royal Brompton Hospital, Dovehouse Street, London SW3 6LY on 25-28 November 1996. For further details please contact the Postgraduate Education Centre, National Heart and Lung Institute, Dovehouse Street, London SW3 6LY, UK. Telephone: 01713518172 . Fax: 0171 3763442 .

\section{CORRECTION}

\section{Home assessment of peak inspiratory flow through the Turbohaler in asthmatic patients}

In the paper entitled "Home assessment of peak inspiratory flow through the Turbohaler in asthmatic patients" by $\mathrm{R} \mathrm{J}$ Meijer et al which appeared on pages 433-4 of the April issue there was a typographical error in the labelling on the $\mathrm{X}$ axis of figure 2 . A correct version of the figure is reproduced below.

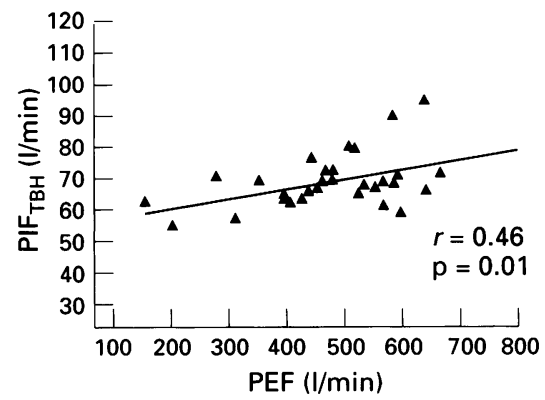

Figure 2 Correlation between peak inspiratory flow through the Turbohaler $\left(P I F_{T B H}\right)$ and peak expiratory flow (PEF) at home. Data points are shown as individual means. 